\title{
Erratum to: Impacts of climate change on European hydrology at 1.5, 2 and 3 degrees mean global warming above preindustrial level
}

\author{
Chantal Donnelly ${ }^{1}$ - Wouter Greuell ${ }^{2}$. \\ Jafet Andersson ${ }^{1}$ - Dieter Gerten ${ }^{3}$. \\ Giovanna Pisacane $^{4}$ - Philippe Roudier ${ }^{5}$. Fulco Ludwig ${ }^{1}$
}

Published online: 11 July 2017

(C) Springer Science+Business Media B.V. 2017

\section{Erratum to: Climatic Change (2017) 143:13-26 \\ DOI 10.1007/s10584-017-1971-7}

Some important funding information is missing from the Acknowledgements section of this article. Please find the corrected paragraph here:

Acknowledgements The research leading to these results has received funding from the European Union Seventh Framework Programme (FP7/2007-2013) under the project IMPACT2C: Quantifying projected impacts under $2{ }^{\circ} \mathrm{C}$ warming (grant agreement no. 282746) and the Swedish Civil Contingencies Agency under the project HazardSupport (dnr. 2015-3631). We are grateful for use of the regional downscaling and bias correction done within that project.

The online version of the original article can be found at http://dx.doi.org/10.1007/s10584-017-1971-7

Chantal Donnelly

chantal.donnelly@smhi.se

Swedish Meteorological Institute, Norrköping, Sweden

2 Earth System Sciences Group, Wageningen University and Research Centre (WUR), Wageningen, The Netherlands

3 Potsdam Institute for Climate Impact Research, 14412 Potsdam, Germany

4 ENEA, Rome, Italy

5 Agence Française de Développement, Paris, France 